CORRECTION

https://doi.org/10.1038/s41586-019-1380-3

\section{Author Correction: Genomic characterization of metastatic breast cancers}

François Bertucci, Charlotte K. Y. Ng, Anne Patsouris, Nathalie Droin, Salvatore Piscuoglio, Nadine Carbuccia, Jean Charles Soria, Alicia Tran Dien, Yahia Adnani, Maud Kamal, Séverine Garnier, Guillaume Meurice, Marta Jimenez, Semih Dogan, Benjamin Verret, Max Chaffanet, Thomas Bachelot, Mario Campone, Claudia Lefeuvre, Herve Bonnefoi, Florence Dalenc, Alexandra Jacquet, Maria R. De Filippo, Naveen Babbar, Daniel Birnbaum, Thomas Filleron, Christophe Le Tourneau \& Fabrice André

Correction to: Nature https://doi.org/10.1038/s41586-019-1056-z, published online 22 May 2019.

In Fig. 1 of this Letter, the coloured plots of significantly mutated genes (at the bottom left) were incorrect, having 23 instead of 21 plots. This error does not affect the results and conclusions of this paper. Figure 1 has been corrected in the online version of this paper.

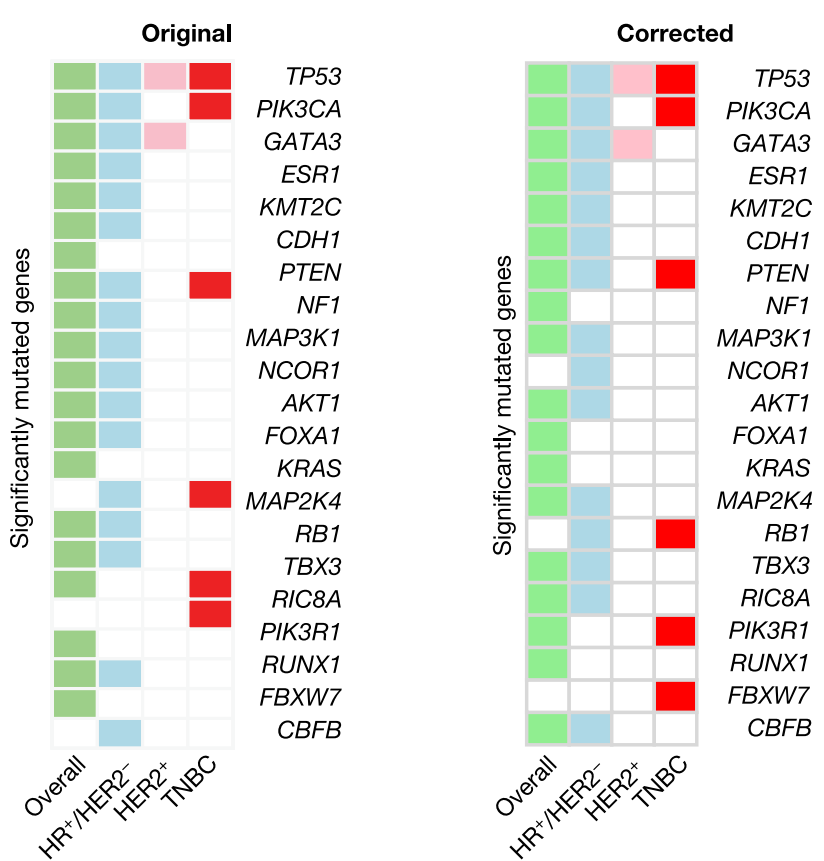

Fig. 1 | This figure shows the original and corrected plots of the significantly mutated genes in Fig. 1. 